\title{
Diversity, host-specificity and stability of sponge-associated fungal communities of co-occurring sponges
}

\author{
Mary THD Nguyen ${ }^{1}$, Torsten Thomas ${ }^{\text {Corresp. } 1}$ \\ ${ }^{1}$ Centre for Marine Bio-Innovation and School of Biological, Earth and Environmental Sciences, University of New South Wales, Sydney, Australia \\ Corresponding Author: Torsten Thomas \\ Email address: t.thomas@unsw.edu.au
}

Fungi play a critical role in a range of ecosystems, however their interactions and functions in marine hosts, and particular sponges, is poorly understood. Here we assess the fungal community composition of three co-occurring sponges (Cymbastela concentrica, Scopalina sp., Tedania anhelans) and the surrounding seawater over two time points to help elucidate host-specificity, stability and potential core members, which may shed light into the ecological function of fungi in sponges. The results showed that ITS-amplicon-based community profiling likely provides a more realistic assessment of fungal diversity in sponges than cultivation-dependent approaches. The sponges studied here were found to contain phylogenetically diverse fungi (eight fungal classes were observed), including members of the family Togniniaceae and the genus Acrostalagmus, that have so far not been reported to be cultured from sponges. Fungal communities within any given sponge species were found to be highly variable compared to bacterial communities, and influenced in structure by the community of the surrounding seawater, especially considering temporal variation. Nevertheless, the sponge species studied here contained a few 'variable/core' fungi that appeared in multiple biological replicates and were enriched in their relative abundance compared to seawater communities. These fungi were the same or highly similar to fungal species detected in sponges around the world, which suggests a prevalence of horizontal transmission where selectivity and enrichment of some fungi occur for those that can survive and/or exploit the sponge environment. Our current (sparse) knowledge about sponge-associated fungi thus indicate that fungal communities may perhaps not play as an important ecological role in the sponge holobiont as its bacterial or archaeal symbionts. 
1 Diversity, host-specificity and stability of sponge-associated fungal communities of co2 occurring sponges

3

4 Mary T. H. D. Nguyen and Torsten Thomas

6 Centre for Marine Bio-Innovation and School of Biological, Earth and Environmental Science,

7 University of New South Wales, Sydney, Australia;

8

9 Corresponding Author: Torsten Thomas, Centre for Marine Bio-Innovation and School of

10 Biological, Earth and Environmental Science, University of New South Wales, Sydney, New

11 South Wales 2052, Australia, telephone: +61-2-93853467, fax: +61-2-93851779, email:

12 t.thomas@unsw.edu.au 


\section{Abstract}

18 Fungi play a critical role in a range of ecosystems, however their interactions and functions in marine hosts, and particular sponges, is poorly understood. Here we assess the fungal community composition of three co-occurring sponges (Cymbastela concentrica, Scopalina sp., Tedania anhelans) and the surrounding seawater over two time points to help elucidate host-specificity, stability and potential core members, which may shed light into the ecological function of fungi in sponges. The results showed that ITS-amplicon-based community profiling likely provides a more realistic assessment of fungal diversity in sponges than cultivation-dependent approaches. The sponges studied here were found to contain phylogenetically diverse fungi (eight fungal classes were observed), including members of the family Togniniaceae and the genus Acrostalagmus, that have so far not been reported to be cultured from sponges. Fungal communities within any given sponge species were found to be highly variable compared to bacterial communities, and influenced in structure by the community of the surrounding seawater, especially considering temporal variation. Nevertheless, the sponge species studied here contained a few 'variable/core' fungi that appeared in multiple biological replicates and were enriched in their relative abundance compared to seawater communities. These fungi were the same or highly similar to fungal species detected in sponges around the world, which suggests a prevalence of horizontal transmission where selectivity and enrichment of some fungi occur for those that can survive and/or exploit the sponge environment. Our current (sparse) knowledge about sponge-associated fungi thus indicate that fungal communities may perhaps not play as an important ecological role in the sponge holobiont as its bacterial or archaeal symbionts. 


\section{Introduction}

Fungi are ecologically important in terrestrial environments performing vital functions as freeliving decomposers, nutrient cyclers, parasites, commensals and mutualists (Webster and Weber, 2007). The global fungal richness has been estimated between 1.5-1.6 million species (Hawksworth, 1991, Hawksworth, 2001). Most of our current understanding of the ecology and function of fungi is derived from studies of cultured fungal isolates, mostly from terrestrial environments (Richards et al., 2012). In comparison, little is known about the diversity and ecology of fungi in the marine environment as it is estimated that only $\sim 0.6 \%$ of all cultured and studied fungi are marine derived (Burgaud et al., 2009, Kis-Papo, 2005). Marine fungi form an ecological, but not a taxonomic group and can be classified, according to Kohlmeyer and Volkmann-Kohlmeyer (1990), as "obligate marine" (i.e. those that grow and sporulate exclusively in marine habitats) and "facultative marine" (i.e. those that are from freshwater and terrestrial milieus, but able to grow and possibly sporulate in marine environments). As more studies emerge, marine fungi are increasingly considered to play an important ecological role as saprotrophs, parasites, commensals or mutualists in the marine ecosystem (Hyde et al., 1998), and have thus been reported to be associated with higher marine organisms, such as macroalgae, corals and sponges (Richards et al., 2012).

Sponges are sessile, filter-feeding organisms that play a crucial role in benthic communities through nutrient cycling, including carbon, silicon, oxygen and nitrogen, and the provision of habitats for a range of fauna and flora (Bell, 2008). Sponges can harbour microbial communities from all three domains of life, archaea, bacteria and eukaryotes (fungi, microalgae and protozoa), which can account for up to 40-60\% of the sponge's volume in some species (Hentschel et al., 2006). The diversity of sponge-associated bacteria and archaea has been extensively studied showing often the presences of stable, sponge-specific symbiont communities (Thomas et al., 2016, Hentschel et al., 2003, Hentschel et al., 2002, Webster and Taylor, 2012). In contrast, eukaryotic symbionts have received little attention and even less is known about their function and interaction with the sponge host (Taylor et al., 2007, Webster and Taylor, 2012).

To date, 22 orders of Ascomycota and eight orders of Basidiomycota have been found in sponges (Yu et al., 2013), largely through culture-dependent approaches (Morrison-Gardiner, 2002, Wang et al., 2008, Li and Wang, 2009), which aimed at the discovery of biologically active, 
secondary metabolites (Taylor et al., 2007, Baker et al., 2009, He et al., 2014, Holler et al., 2000, Liu et al., 2010). Ubiquitous fungal genera (e.g. Aspergillus, Penicillium, Trichoderma and Acremonium) have been isolated from multiple sponge species worldwide suggesting these may be either "generalist" and/or are preferentially detected due to their ease of cultivation (Richards et al., 2012). In fact, cultivation conditions as well as sample preparation methods have likely biased the comparison between studies (Anderson et al., 2003). To overcome these issues, molecular techniques that amplify and sequence the 18S rRNA gene or the internal transcribed spacer (ITS) of the ribosomal RNA gene operon directly from DNA extracted from samples have been applied to examine fungal diversity in a range of environments (De Beeck et al., 2014, Döring et al., 2000, Gardes and Bruns, 1993, Anderson et al., 2003). PCR-primer bias towards certain fungal groups or non-target DNA, however, are drawbacks of this approach (Wang et al., 2014). Culture-dependent and culture-independent approaches have thus been shown to capture different parts of fungal communities in deep-sea sediments (Singh et al., 2012, Jebaraj et al., 2010) and soil (Jeewon and Hyde, 2007).

Few studies have considered the diversity, ecological function or the nature of sponge-fungi interactions. Recent studies on fungal diversity in sponges present conflicting reports on their host-specificity. For example, Gao et al. (2008) reported distinct fungal communities between two co-occurring Hawaiian sponges and also to the surrounding seawater using denaturing gradient gel electrophoresis (DGGE)-based ITS analysis. He et al. (2014) found that the fungal communities differed on the order level between some Antarctic sponge species and RodriguezMarconi et al. (2015) further suggested that there is a high degree of host specificity of fungi in Antarctic sponges. However, it should be noted that both studies lacked biological replications. In contrast, Naim et al. (2017) recently reported low host-specificity and suggested the presence of fungi in sponges to be rather 'accidental'.

Aside from these community-wide studies, there has been some observational evidence for sponge-fungi interactions. This includes the vertical transmission of an endosymbiotic yeast in the marine sponge Chondrilla sp. (Maldonado et al., 2005) and the putative horizontal gene transfer of a fungal mitochondrial intron into the genome of the sponge Tetilla sp. (Rot et al., 2006). In addition, the sponge Suberites domuncula has been suggested to recognise fungi via the 
100 D-glucans on their surfaces (Perović-Ottstadt et al. 2004) and ascomycetes of the genus 101 Koralionastes have been reported to have a unique physical association with crustaceous sponges 102 (Kohlmeyer and Volkmann-Kohlmeyer, 1990). And finally, the ability of many sponge-derived 103 fungi to produce novel bioactive compounds have been suggested to contribute to host defence 104 (Holler et al., 2000, Imhoff, 2016, Proksch et al., 2008, Proksch et al., 2003, Wiese et al., 2011, $105 \mathrm{Yu}$ et al., 2013). These studies indicate that certain close symbiotic interactions between fungi 106 and sponges exist, however this conclusion seems to be not necessarily supported by culture107 dependent and -independent community-wide analyses.

108 The aim of the current study is to assess the diversity of the fungal community of sponges using 109 cultivation-based and cultivation-independent ITS community profiling to examine their 110 suitability to describe sponge-associated fungal diversity. Fungal communities of three co111 occurring sponges and the surrounding seawater were assessed over two time points to help 112 elucidate host-specificity, stability and potential core members, which may shed light into the 113 ecological function of fungi in sponges.

\section{Materials and Methods}

115 Sample collection

116 Sponges were sampled at Bare Island in Botany Bay, NSW, Australia (33 59'S, $\left.151^{\circ} 14^{\prime} \mathrm{E}\right)$ on 117 two separate occasions, on the 13-11-2014 and on the 4-5-2016. At each sampling event, 118 seawater samples (SW) and three specimens of Cymbastela concentrica (C), Scopalina sp. (S) 119 and Tedania anhelans (T) sponges were collected by SCUBA diving at a depth of 7-10 m and 120 within an area of about 20x20m. Sampling of sponges was performed under the scientific 121 collection permit P13/0007-1.1 issued by the New South Wales Department of Primary 122 Industries. Sponge specimens were identified by the morphological characteristics and their 123 locality as per our previous study (Fan et al., 2012). Samples were placed individually into 124 Ziploc $\AA$ bags with seawater and then transported in buckets filled with seawater to the laboratory 125 at ambient temperature (travel time approximately $30 \mathrm{~min}$ ). Sponges samples were processed 126 immediately for cultivation or frozen at $-80^{\circ} \mathrm{C}$ for subsequent DNA extraction. Seawater (200 $127 \mathrm{~mL}$ ) were vacuum filtered onto $0.22 \mu \mathrm{m}$ filters (Whatman, Sigma-Aldrich) in replicates and used 128 immediately for cultivation or frozen at $-80^{\circ} \mathrm{C}$ for subsequent DNA extraction. 


\section{Cultivation of fungi}

131 Sponge tissues were processed as described by Wang et al. (2008). Briefly, sponge samples were 132 washed three times in sterile calcium/magnesium-free seawater (CMFSW; $25 \mathrm{~g} \mathrm{NaCl,} 0.8 \mathrm{~g} \mathrm{KCl}$, $1331 \mathrm{~g} \mathrm{Na}_{2} \mathrm{SO}_{4}$ and $0.04 \mathrm{~g} \mathrm{NaHCO}_{3}$ per $1 \mathrm{~L}$ ) to remove natural seawater from the sponge and the 134 outer surfaces of the samples were sterilized with $70 \%$ ethanol. Two different cultivation 135 methods were applied: a) sponges were sliced into thin sections (approximately $1 \mathrm{~cm}^{2}$ and 1 $1362 \mathrm{~mm}$ thick) and placed directly onto agar plates (listed below) and b) sponge tissue was 137 homogenized at maximum speed for 50-60s with a dispersing homogenizer (Ulta-Turrax TR50, 138 IKA). The homogenate was diluted with sterile seawater $\left(10^{0}, 10^{-1}, 10^{-2}\right)$ and $100 \mu \mathrm{L}$ of each 139 dilution was plated. For seawater samples two methods were applied: a) $200 \mathrm{~mL}$ of seawater were vacuumed filtered onto $0.22 \mu \mathrm{m}$ Whatman filters (Sigma-Aldrich) and filters were directly placed onto agar plates and b) $1 \mathrm{~mL}$ of seawater was directly plated onto agar plates. Triplicates of each sample and preparation method were plated onto three different media: 1) peptone yeast glucose agar (PYG; 1.0 g glucose, 0.1 g yeast extract, $0.5 \mathrm{~g}$ peptone and $15 \mathrm{~g}$ Difco-bacto agar per $1 \mathrm{~L}, \mathrm{pH} 8.0$ ); 2) Dextrose potato agar (BD Difco ${ }^{\mathrm{TM}}$ ) and 3) Gause I (20 g starch, $1.0 \mathrm{~g} \mathrm{KNO}$, $0.5 \mathrm{~g} \mathrm{~K}_{2} \mathrm{HPO}_{4}, 0.5 \mathrm{~g} \mathrm{MgSO}_{4} \cdot 7 \mathrm{H}_{2} \mathrm{O}, 0.5 \mathrm{~g} \mathrm{NaCl}, 0.01 \mathrm{~g} \mathrm{FeSO}_{4}$ and $15 \mathrm{~g}$ Difco-bacto agar per 1 L). All media was made up with $0.22 \mu \mathrm{m}$ filtered and autoclaved seawater from Bare Island. The plates were incubated at $18-20^{\circ} \mathrm{C}$ for $1-2$ months until fungal growth was visible. Every isolate was picked and transferred onto new PYG, Potato dextrose and Gause I agar plates. The resulting pure cultures were stored in sterile artificial seawater (ASW; $23.38 \mathrm{~g} \mathrm{NaCl}, 2.41 \mathrm{~g}$ $\mathrm{MgSO}_{4}, 1.19 \mathrm{~g} \mathrm{MgCl}_{2}, 1.47 \mathrm{~g} \mathrm{CaCl}_{2} .2 \mathrm{H}_{2} \mathrm{O}, 0.75 \mathrm{~g} \mathrm{FCl}$ and $0.17 \mathrm{~g} \mathrm{NaHCO}_{3}$ per $1 \mathrm{~L}$ ) in $2 \mathrm{~mL}$ cryogenic vials (Sigma-Aldrich) at $4^{\circ} \mathrm{C}$.

152

153

154

155

156 157

\section{Identification of fungal isolates}

DNA extraction from fungal isolates were conducted using the CTAB method (Lee, 1988) with modifications. Briefly, fungal mycelia were added to $1 \mathrm{~mL}$ of CTAB buffer, 3-6 $1 \mathrm{~mm}$ glass beads (Sigma-Aldrich) and $10 \mu \mathrm{L}$ of mercaptoethanol and bead beaten (TissueLyser II, Qiagen) at maximum speed for 8 minutes. Samples were heated at $65^{\circ} \mathrm{C}$ for 10 minutes, then extracted with phenol:chloroform:isoamyl alcohol (25:24:1) and DNA was precipitated with isopropanol. 
158 DNA was dissolved in $50 \mu \mathrm{L}$ of pure water and used for PCR amplification. PCR was conducted 159 in $25 \mu \mathrm{L}$ reactions consisting of $12.5 \mu \mathrm{L}$ of Econotaq master mix, $9.5 \mu \mathrm{L}$ of water, $1 \mu \mathrm{L}$ of each 160 forward primer ITS1f-F (10 $\mu \mathrm{M})$ (5' TTGGTCATTTAGAGGAAGTAA 3') and reverse ITS4 161 (5' TCCTCCGCTTATTGATATGC 3') (White et al. 1990) and $1 \mu \mathrm{L}$ of template DNA. PCR 162 conditions were $95^{\circ} \mathrm{C} / 2 \mathrm{~min}$, then $94^{\circ} \mathrm{C} / 30 \mathrm{~s}, 53^{\circ} \mathrm{C} / 30 \mathrm{~s}, 72^{\circ} \mathrm{C} / 45 \mathrm{~s}$ for 35 cycles and $72^{\circ} \mathrm{C} / 5$ 163 min. Amplicon products were assessed by gel electrophoresis, cleaned with Exosap-IT (Thermo 164 Fisher Scientific, CA, USA) and sequenced with the BigDye Terminator v3.1 chemistry 165 (Applied Biosystems, Austin, TX, USA) and an Applied Biosystems 3730 DNA Analyzer at the 166 Ramaciotti Centre for Genomics (University of New South Wales, NSW, Australia). Sequences 167 were manually quality trimmed using Sequences Scanner v1.0 software and forward and reverse 168 sequencing reads were assembled (when applicable) using BioEdit v7.2.5 (Ibis Biosciences, 169 Carlsbad, CA, USA).

\section{Sequence analysis of ITS amplicon community profiling}

172 Total DNA were extracted from sponge samples and seawater filters from the two sampling time 173 points using the Power Soil DNA Isolation kit (Qiagen, Germany) following the manufacturer's instructions. Fungal ITS amplicon sequencing was conducted by Molecular Research LP (Mr. DNA, Texas, U.S.A) using the IST1f-ITS4 primers. PCRs were conducted with a HotStarTaq 176 Plus Master Mix kit (Qiagen, USA) under the following conditions: $94{ }^{\circ} \mathrm{C}$ for 3 minutes, 177 followed by 28 cycles of $94^{\circ} \mathrm{C}$ for 30 seconds, $53{ }^{\circ} \mathrm{C}$ for 40 seconds and $72{ }^{\circ} \mathrm{C}$ for 1 minute, and a final elongation step at $72{ }^{\circ} \mathrm{C}$ for 5 minutes. After amplification, PCR products are checked in $2 \%$ agarose gel to determine the success of amplification and the relative intensity of bands. PCR samples were pooled together in equal proportions based on their molecular weight and DNA

181

182 183 184 185 186 187 concentrations and purified using calibrated Ampure XP beads. The pooled and purified PCR products were then used to prepare a Illumina DNA library. Sequencing was performed on the Illumina MiSeq sequencing platform and 2x300 bp chemistry.following the manufacturer's guidelines. Because of the variable length of the ITS region (400-800 bp), forward and reverse sequences could often not be assembled into contigs. In addition, reverse reads had generally lower quality than the forward reads and therefore only the forward ITS amplicon sequence reads $(300 \mathrm{bp})$ were quality filtered and analysed together with the isolate sequences from above. All 
188 sequences were quality filtered with a maximum expected error threshold of 1 and minimum 189 length of $250 \mathrm{bp}$ and then clustered into operational taxonomic units (OTUs) at 97\% similarity 190 using the UPARSE pipeline (Usearch v9.2) (Edgar, 2013). Chimeras were removed using 191 UCHIME (Edgar et al., 2011) and taxon classification of OTUs were conducted using the 192 UNITE ITS reference database (Abarenkov et al., 2010) with the utax command in the Usearch 193 program. Lowest taxon classification at a confidence level of $70 \%$ or above were considered and 194 checked with the Basic Local Alignment Search tool (BLASTn) against the non-redundant 195 nucleotide database (NT) from the National Centre for Biotechnology Information (NCBI). Non196 fungal sequences were removed from further analysis. The commands for the entire ITS 197 amplicon analysis are available in the Supplemental Information. Raw ITS-amplicon sequences 198 are available through the NCBI Sequence Read Archive (SRA) under Bioproject ID: 199 PRJNA419577, accession number SRP125576.

\section{Sequence analysis of $16 S$ rRNA community profiling}

202 Given the high variability of fungal communities observed between biological replicates (see 203 below), we wanted to understand if this is a peculiar aspect of the samples we took and how we 204 processed them or if this is due to real biological variation. We therefore also analysed all samples for the bacterial community composition, which has been shown to be very consistent

206 between replicates of the three sponges analysed here (Fan et al. 2012, Esteves et al. 2016).

207 Bacterial 16S rRNA gene amplicon sequencing of sponge and seawater samples were therefore 208 conducted using primers 515F (5'-GTG CCA GCM GCC GCG GTA A-3') and 806R (5'-GGA CTA CHV GGG TWT CTA AT-3') with the Illumina MiSeq sequencing platform and 2x250 bp chemistry at the Ramaciotti Centre for Genomics (University of New South Wales, Sydney, NSW, Australia), according to the methodology described by Caporaso et al. (2012). Bacterial 16S rRNA sequences were processed using the MiSeq SOP pipeline (Mothur v1.37.3) (Schloss et al., 2009). Briefly, raw forward and reverse sequence reads were assembled into contigs, quality filtered and aligned to the SILVA 16S rRNA gene reference alignment v102 (Quast et al., 2012). Sequences were filtered to only include overlapping regions, pre-clustered to merge all sequences within three mismatches (difference $=3$ ) and checked for chimeras using the UCHIME algorithm (Edgar et al., 2011). To separate chloroplasts from cyanobacteria, sequences were first 
218 classified using the SILVA reference v119 (Quast et al., 2012) with a 60\% confidence threshold

219 and sequences classified as chloroplasts were removed. The rest of the sequences were re220 classified using the RDP training set release 9 (Cole et al., 2013) and sequences classified as 221 "unknown" or "mitochondria" were removed before clustering into OTUs at 97\% similarity.

222 OTU matrix was then sub-sampled to the size of the smallest sample (4193 sequences). The commands for this analysis are available in the Supplemental Information.

224

225

226

227

228

229

230

231

232

233

234

235

236

237

238

239

240

241

242

243

244

245

246

\section{Statistical analysis}

The fungal OTU matrix of sponge and seawater samples were used to calculate the species richness estimate (Chao1) and Shannon's index using the summary.single command in Mothur v1.39.0. Fungal community coverage was estimated using Good's coverage (= 1- (number of singleton OTUs/number of reads)). Comparison of beta-diversity was conducted with permutational multivariate analysis of variance (PERMANOVA) (Anderson, 2001) of BrayCurtis dissimilarities of relative abundance and presence-absence values at the OTU level. Variability of communities was analysed using Multivariate Homogeneity of Group Dispersions (PERMDISP) (Anderson et al., 2006, Anderson, 2006) based on Bray-Curtis dissimilarities. Heatmap and statistical analysis were performed in the $\mathrm{R}$ statistical program language ( $\mathrm{R}$ core Team 2014) using the vegan package (Oksanen et al., 2013). Scripts are provided in the Supplemental Information.

\section{Results}

Diversity of fungal communities through culture-dependent and independent methods

Culture-dependent and -independent approaches were applied to sponge and seawater samples collected in 2014. Cultivation yielded a total of 108 isolates and after redundant sequences were removed, it resulted in 42 unique isolate sequences (see Supplemental Table S1 for details), which clustered into 8 OTUs at 97\% similarity. 26 OTUs were obtained via ITS-amplicon sequencing clustered at $97 \%$ similarity. Cultivation obtained one fungal division, Ascomycota, and four fungal orders (Eurotiales, Hypocreales, Diaporthales and Capnodiales) compared to ITS-amplicon sequencing, which obtained three divisions (Ascomycota, Basidiomycota and 
247 Glomeromycota) and 12 orders (Pleosporale, Capnodiales, Eurotiales, Leotiales, Malasseziales, 248 Xylariales, Helotiales, Lecanorales, Teloschistales, Hypocreales, Agaricales and Diaporthales)

249 (Figure 1). Significant differences (PERMANOVA P-value $<0.008$ ) in the fungal community 250 compositions were observed overall and for each sponge species and seawater between the 251 cultivation-dependent and -independent assessments (Figure 1), with the cultivation method 252 producing a lower fungal diversity (Shannon's index of $0.77 \pm 0.32$ ) compared to the ITS 253 amplicon sequencing (1.17 \pm 0.54 ; one-way ANOVA, P-value=0.04). Although a higher fungal 254 diversity was obtained by ITS-amplicon-based community profiling, the cultivation method 255 yielded five unique OTUs not present in the ITS amplicon data (Figure 1). OTU_266 256 (Aspergillus sp.), OTU_286 (Acrostalagmus sp.) and OTU_269 (Cladosporium sp.) were only 257 cultivated from T. anhelans, OTU_265 (family Togniniaceae, genus unclassified) was cultivated 258 from Scopalina sp., and OTU_264 (Trichoderma sp.) was cultivated from C. concentrica, 259 Scopalina sp. and seawater. Three OTUs assigned to the genus Penicillium were found to 260 overlap between the two methods (OTU_119, OTU_165 and OTU_9). OTU_119 was commonly 261 cultivated from all sample types and found once in T. anhelans ITS-amplicon sequencing. The 262 most common OTUs detected in the ITS amplicon data were OTU_4 (Epicoccum sp.) and 263 OTU_6 (Cladosporium sp.) and was observed in all sample types (i.e. three sponge species and 264 seawater) (Figure 1).

265

266

Analysis of the temporal stability and host-specificity of sponge-associated fungal communities

267 Since cultivation recovered only a smaller proportion of the total fungal diversity found 268 compared to ITS-amplicon sequencing, the latter approach was used to analyse temporal changes 269 and specificity of OTUs to sponge species. A larger number of quality-filtered sequences were 270 obtained from samples collected on the 4-5-2016 (average 13,136 sequences per sample; range 2716578 - 30,977) compared to the collection effort on the 13-11-2014 (4,062 sequences per sample; 27264 - 16,199 range). Sequences were clustered into OTUs at a 97\% similarity and non-fungal 273 sequences were removed leaving a total of 155,298 sequences and 148 OTUs. Estimation of the 274 Chao1, Good's coverage and Shannon's indices were conducted on normalised data (sub275 sampled to 250 sequences), resulting in the removal of samples S_1_14, S_2_14, S_2_16, 276 S_3_14, SW_1_14 and T_3_14 (sample-type_replicate-number_year) (Table 1). Good's 
277 coverage estimates were greater than $94 \%$ for all remaining samples, showing that the majority 278 of OTUs were captured through the ITS-amplicon sequencing effort. Generally, Chao1 estimates 279 positively correlated with the Shannon's diversity index.

281

282

283

284

285

286

287

288

289

290

291

292

293

294

295

296

297

298

299

300

301

302

303

304

305

Due to the filter feeding capacities of sponges, we expect the presence of 'incidental' environmental fungi in our sponge samples. Fungal OTUs were therefore grouped into three categories; 'occasional' (OTUs occurring only once in the six replicates per sample type), 'variable' (OTUs occurring in two to five of the six replicates per sample type) and core OTUs (OTUs occurring in all six replicates per sample type). No core OTUs were observed in $C$. concentrica, Scopalina sp. and seawater, and only one core OTU was observed in T. anhelans (Table 2). Fungal communities of all three sponges were predominantly comprised of 'variable' OTUs ( $>60 \%$ mean relative abundance).

Occasional OTUs were removed to create the 'variable/core' fungal community dataset and was sub-sampled to a size of 250 reads, (S_1_14, S_2_14, S_2_16, S_3_14, S_W1_14 and T_3_14 samples were removed), resulting in a total of 38 OTUs (Figure 2). Similar to the whole community analysis (Table S2), Shannon's diversity indices of the 'variable/core' communities were significantly lower in 2014 compared to 2016 (Table 3). 'Variable/core' communities of $C$. concentrica and seawater were significantly different, but fungal diversity of $T$. anhelans was comparable between the two time points. Temporal samples were combined to compare the community diversity of sponge species and seawater to each other. 'Variable/core' community of Scopalina sp. had the highest Shannon's index followed by T. anhelans, C. concentrica and seawater (Table 3), in contrast to the whole community analysis where the Shannon's index was highest for Scopalina sp., followed by seawater, C. concentrica and T. anhelans (Table S2). However, Shannon's indices for both whole and 'variable/core' communities for all samples were comparable to each other.

Fungal communities were overall quite variable in structure with average distances from the centroid calculated with PERMDISP being 0.57, 0.46, 0.44 and 0.58 for C. concentrica, 
306 Scopalina sp., T. anhelans and seawater, respectively. In contrast, the average distance to 307 centroid for bacterial communities of C. concentrica, Scopalina sp., T. anhelans and seawater 308 were relatively low with values of $0.21,0.17,0.11$ and 0.22 , respectively, and we saw a clear 309 distinction in the composition and structure of these samples types (Figure 3) Despite this 310 relatively high variability in the fungal community, beta-diversity analysis of the whole (Table 311 S3) and 'variable/core' (Table 4) fungal communities showed significant overall differences 312 between samples in 2014 and 2016. C. concentrica and seawater community compositions 313 (presence/absence) were also different between the two time points, in contrast to T. anhelans. 314 However, temporal communities of sponges and seawater did not differ between the two time 315 points based on relative abundances. Beta-diversity analysis further showed that the fungal 316 communities of all three sponge species were comparable to the surrounding seawater. The only 317 difference was observed between fungal community of $T$. anhelans and Scopalina sp., where 318 whole community analysis showed differences only in their compositions, in contrast to the 319 'variable/core' community analysis, where significant differences were seen both in terms of 320 their structure and composition.

32130 out of 32 OTUs observed in sponges were also present in the surrounding seawater, however 32212 of these OTUs were enriched in sponge-associated communities (based on mean relative 323 abundances) (Figure 2 and Table S4). The majority of enriched OTUs were found in more than 324 one sponge species: OTU_6, OTU_5, OTU_10, OTU_7, OTU_8, OTU_11, OTU_12 and 325 OTU_13 were found in all three sponges, OTU_63 and OTU_45 were observed in T. anhelans 326 and Scopalina sp., OTU_14 was observed in C. concentrica and Scopalina sp., and OTU_87 was 327 observed in Scopalina sp. (Figure 2). Two OTUs not found in seawater were OTU_41 328 (Alatospora sp.) (only observed in C. concentrica) and OTU_112 (belonging to the class 329 Agaricomycetes and was unique to Scopalina sp.), and both were highly variable in abundance 330 and sometimes absent across the replicate samples. Fungal communities in sponges were 331 generally dominated by a few OTUs. The top 7, 8 and 4 most abundant OTUs made up $\sim 90 \%$ of 332 the total relative abundance of C. concentrica, Scopalina sp. and T. anhelans, respectively. The 333 most abundant OTU observed across all samples was OTU_6 (Cladosporium sp.), but was most 334 abundantly found in $T$. anhelans with a relative abundance range of $0-99 \%$ across six individual 335 sponge samples. Only one core OTU was found in the sponge T. anhelans (OTU_63) identified 336 as belonging to the class Leotiomycetes.. 
338 Discussion

339 Assessment of fungal diversity in sponges

340 Sponge-associated fungal communities have been studied through culture-dependent (Henríquez 341 et al., 2014, Liu et al., 2010, Wang et al., 2008, Holler et al., 2000, Proksch et al., 2008, Wiese et 342 al., 2011, Yu et al., 2013, Li and Wang, 2009) and culture-independent methods (Gao et al., 343 2008, Naim et al., 2017, He et al., 2014, Passarini et al., 2015, Rodríguez-Marconi et al., 2015, 344 Wang et al., 2014). However, no study has so far combined both approaches to provide insights 345 into the extent to which the two community assessments capture sponge-associated diversity.

346 In this study, 42 fungal isolates were classified into 8 different OTUs (Penicillium spp. (3), 347 Togniniaceae, Acostalagmus sp., Trichoderma sp., Cladosporium sp., and Aspergillus sp.). Three 348 isolates of the genus Penicillium (Eurotiales) were also found in the ITS amplicon sequencing 349 and one isolate (OTU_119) was cultivated from all sample types. Penicillium can be considered 350 as a 'generalist' (or core organism) and is an ubiquitous fungal genus commonly cultured from 351 various environments, including sponges from around the world (Gao et al., 2008, Holler et al., 352 2000, Li and Wang, 2009, Liu et al., 2010, Passarini et al., 2015, Passarini et al., 2013, Paz et al., 353 2010, Pivkin et al., 2006, Proksch et al., 2008, Wang et al., 2008). Fungi from the family 354 Togniniaceae (order Diaporthales) are likely of terrestrial origins as a common genus (Togninia) 355 within is often associated with wilt and disease of woody plants (Crous et al., 1996, Rossman et 356 al., 2007). Acrostalagmus (order Hypocreales) contains pathogenic fungi against animals, plants 357 and humans (Kubicek et al., 2008). Some species of this genus have been isolated from deep-sea 358 sediments and have been reported to produce anti-tumor (Wang et al., 2012) and antifungal 359 compounds (Sato and Kakisawa, 1976, Ellestad et al., 1969). Togniniaceae and Acrostalagmus $360 s p$. so far have not been reported to be cultured from marine sponges, while Trichoderma sp., 361 Aspergillus sp. and Cladosporium sp. have previously been cultivated from various marine 362 sponges (Proksch et al., 2008, Holler et al., 2000, Wang et al., 2008, Paz et al., 2010, Passarini et 363 al., 2013).

364 ITS-amplicon based community profiling captured more fungal diversity (26 OTUs) compared 365 to cultivation (8 OTUs), which is consistent with previous studies examining fungal communities 366 in marine sediments, decaying leaves and soil (Jebaraj et al., 2010, Nikolcheva et al., 2003, 
367 Borneman and Hartin, 2000, Singh et al., 2012). However, similar to the studies of Jabaraj et al. 368 (2010) and Singh et al. (2012), the cultivation yielded also distinct isolates (five) that were not 369 found through the culture-independent method. Three of the unique isolates were cultivated from 370 T. anhelans (OTU_266, OTU_268 and OTU_269), one from Scopalina sp. (OTU_265) and 371 OTU_ 264, which was cultivated from C. concentrica, Scopalina sp. and seawater. This 372 occurrence could be explained by the overall low number of fungal reads obtained for $T$. 373 anhelans and Scopalina samples in 2014, when the cultivation was also performed (Table 1). 374 Low numbers of fungal reads due to the amplification of non-target (e.g. sponge) DNA was also 375 noted as a challenge in previous fungal diversity studies (He et al., 2014, Naim et al., 2017, Gao 376 et al., 2008). Another explanation for the discrepancy between the two methods is that the 377 isolates could belong to the rare biosphere, which is supported by the fact that three of the 378 isolates were unique (i.e. only cultured once) (Table S1). Similarly, the three Penicillium spp., 379 which were found by both methods, were only found in low relative abundances in the ITS380 amplicon sequencing data. This indicates that fungal cultivation, even under the various conditions tried here, does not capture abundant community members in sponges, but rather

382

383 384 385 386 387 388 those that are relatively rare. This situation is analogous to what has been seen in many studies examining bacterial communities in sponges (Webster and Hill, 2001, Esteves et al., 2016, Hentschel et al., 2001, Muscholl-Silberhorn et al., 2008, Li et al., 2007). Our results indicate that ITS-amplicon-based community profiling therefore likely provides a more realistic assessment of fungal diversity in sponges and thus should be seen as the "gold standard" for community assessment, similar to what has been proposed for fungal diversity research in other environments (Pang and Mitchell, 2005, Jeewon and Hyde, 2007).

\section{Host specificity of sponge-associated fungi}

Li and Wang (2009) have previously classified fungi found in sponges into three groups: 'sponge-generalists' (i.e. found in all sponge species), 'sponge-associates' (i.e. found in more than one sponge species), and 'sponge-specialists' (i.e. found in only one sponge species). This classification is very limited and dependent on a) the number of sponge species studied, b) the methods used (culture-dependent or -independent approach (see above), and c) experimental design (use (or lack) of biological replicates or seawater reference communities). These limitations have been highlighted by $\mathrm{Yu}$ et al. (2013) in their summary of sponge-associated 
397 fungi reported since 1996. The summary illustrates differences in classification of the same 398 fungal genus in different studies. For example, the fungal genera Fusarium and Trichoderma 399 were classified as 'sponge generalists' according to Menezasa et al. (2010), but were classified as 400 'sponge-associates' by Höller et al. (2000) and Li and Wang (2009), and were completely absent 401 in various sponges investigated by Gao et al. (2008) and Pivkin et al. (2006). Therefore, one 402 should be careful when using these terminologies for host-specificity of fungal genera. Another 403 challenge in determining the specificity of sponge-associated fungi is the filter-feeding capacity 404 of sponges that brings large amounts of seawater along with all its constituents into the sponge 405 tissue. Studies that are based on the once-off, presence-absence measurement of isolates 406 (Thirunavukkarasu et al., 2012, Paz et al., 2010, Liu et al., 2010, Li and Wang, 2009) or sequences (Gao et al., 2008, He et al., 2014, Zhang et al., 2016, Rodríguez-Marconi et al., 2015) to support claims of specificity, could therefore be misleading as fungi found inside the sponge

409

410

411

412

413

414

415

416

417

418

419

420

421

422

423

424

425

426

427 might simply just be accidentally trapped, rather than having any meaningful interaction with the sponge. Indeed, studies on bacterial communities in sponges have found that ecologically important organisms are consistently present in the sponge and usually at high relative abundances (Thomas et al., 2016, Fan et al., 2012, Hentschel et al., 2003, Hentschel et al., 2002, Lee et al., 2011, Wilkinson and Fay, 1979). Therefore, we propose and recommend implementing a different guideline to the above classifications, where 'occasional' and 'variable/core' fungi can be defined by examining biological replicate samples over time. 'Variable/core' fungi that are found in combination with high relative abundances compared to the surrounding environment (i.e. seawater) should then be considered 'sponge-enriched'. Implementing these guidelines, our study revealed that 'variable/core' fungal communities in sponges have low diversity ( $\leq 28$ fungal OTUs were observed in each sponge species), high variability and that the majority of fungal OTUs were not specifically enriched in any of the sponge species investigated here. These findings are consistent with a recent study by Naim et. al. (2017). In contrast, the bacterial communities of the sponges studied here have previously been shown to have diverse and host-specific sponge-enriched bacterial phyla, which was consistent over time and space (Fan et al. 2012, Esteves et al. 2016). Furthermore, bacterial communities had low variability and were distinct from the bacterial community in the surrounding seawater (Thomas et al., 2016, Fan et al., 2012). Indeed we could reproduce this low variability and distinctive composition of bacterial communities (see Figure 3) using the same 
428 technical approaches and DNA extracts used for the fungal analysis, indicating that the high 429 variability in the fungal communities truly reflects fundamental differences in the ecology of 430 these two microbial groups.

431 Fungal communities in the three sponges studied here appear to be largely influenced by the

432

433

434

435

436

437

438

439

440

441

442

443

444

445

446

447

448

449

450

451

452

453

454

455

456

457

community of the surrounding seawater. This is broadly reflected in the higher fungal diversity observed in 2016 compared to 2014, in both the seawater and in all sponges. However, the degree of influence by the surrounding seawater appears to differ for different sponge species. Fungal communities in $T$. anhelans did not significantly differ between the two time points, in contrast to $C$. concentrica and seawater. Additionally, fungal communities of $T$. anhelans and Scopalina $s p$. were found to be significantly different between each other suggesting that the two sponge species may exert different selective pressures on their fungal communities. Differences in the relative abundances of the same OTUs in the sponges further support the occurrence of preferential interactions of fungi with different sponge species. For example, OTU_10 was found in T. anhelans, Scopalina sp. and C. concentrica with mean relative abundance of $0.09 \% \pm 0.21$ (range of $0-0.43 \%$ ), $1.8 \% \pm 3.6$ (range of $0-9.2 \%$ ) and $16.7 \% \pm 38$ (range of $0-94.7 \%$ ), respectively.

\section{Potential roles of sponge-associated fungi}

Seven out of the 12 'sponge-enriched' OTUs were unable to be classified to a genus level, which indicates that they are either novel, yet-to-be-studied organisms or their ITS sequences are not available for the databases we used (Table S5). The seven OTUs could be identified to the lowest taxonomic classification as: kingdom fungi (1), class Lecanoromycetes (2), Leotiomycetes (1), Agaricomycetes (1) and within class Agaricomycetes orders Pleosporales (1) and Agaricales (1). The other five sponge-enriched OTUs were classified as Cladosporium sp. (OTU_6), Fusarium sp. (OTU_8), Aureobasidium sp. (OTU_5), Curvularia sp. (OTU_7), and Beauveria sp. (OTU_13). OTU_112 and OTU_41 were found exclusively in Scopalina sp. and C. concentrica, respectively. OTU_112 was classified to belong to class Agaricomycetes, which contains saprotrophs, pathogens and mutualists (Hibbett et al., 2014). Agaricomycetes were found frequently in this study, in fact eight out of 10 Basidiomycota fungi observed belong to this class. Sponge-enriched order Agaricales and Polyporales (within class Agaricomycetes) have also been detected in other marine sponges (He et al., 2014, Naim et al., 2017) and corals (Amend et al., 
458 2012). OTU_41 (Alatospora sp., order Leotiales) has not been previously reported in marine 459 sponges. Alatospora spp. are commonly associated with decaying wood/leaves in fresh water 460 streams (Das et al., 2008, Hosoya and Tanaka, 2007, Sridhar and Kaveriappa, 1989). Together 461 this shows that fungi with potential saprophytic properties are widespread in sponges and 462 indicates that they may exploit the nutrient rich environment of the sponge host and/or could 463 contribute to nutrient uptake via the breakdown of plant-derived detritus or plankton filtered 464 from the surrounding seawater (Zhang et al., 2006, Hyde et al., 2013, Hibbett et al., 2014).

One core OTU (OTU_63) detected in T. anhelans was classified belonging to the class

467

468

469

470

471

472

473

474

475

476

477

478

479

480

481

482

483

484

485

486

487

488
Leotiomycetes. Interestingly, Leotiomycetes were prevalently cultivated (75\% of total isolates)

from Antarctic sponges, where a third of the fungal isolates were classified to genus Geomyces and had strong antimicrobial activity. Another third of the isolates could not be identified to a genus level (Henríquez et al., 2014), indicating that this class has much unexplored genus-level diversity. More studies on Leotiomycetes in the future are essential to help elucidate its potential ecological function in sponges.

The class Lecanoromycetes (mostly enriched in T. anhelans) contains most of the lichen-forming fungal species (Miadlikowska et al., 2006). An OTU belonging to the order Telochistales (class Lecanoromycetes) was also found in sponge Halichondrida panicea (an encrusting sponge) and was closely related to a lichen-forming fungi isolate (Naim et al., 2017). The lichen-forming genus Koralionastes has been further reported to have a unique physical association with crustaceous sponge and was postulated to be nutritionally dependent on the sponges (Kohlmeyer and Volkmann-Kohlmeyer, 1992). Lichen have been reported to facilitate the destruction of rocks and provide the adjacent water layers with nutrients and trace elements that can benefit hydrobionts, including sponges (Kulikova et al., 2013). This raised the possibility that the presence of Lecanoromycetes in $T$. anhelans (relative abundance range of $0-0.33 \%$ ) and in sponge $H$. panicea may arise from a close co-existence of crustose lichen and encrusting sponges on rock fragments (Suturin et al., 2003).

OTU_6 (Cladosporium sp.) and OTU_8 (Fusarium sp.) belong to genera that are known to be saprotrophs, have previously been isolated from various marine sponges (Menezes et al., 2010, 
489 Wang et al., 2008, Paz et al., 2010, Thirunavukkarasu et al., 2012, Zhou et al., 2011, Liu et al., 490 2010, Ding et al., 2011, Li and Wang, 2009, Proksch et al., 2008) and have been reported to 491 produce bioactive compounds (Gesner et al., 2005, Wiese et al., 2011, Jadulco et al., 2002). For 492 example, Cladosporium herbarum isolated from sponges (Callyspongia aerizusa, Aplysina 493 aerophoba and Callyspongia aerizusa) produced various different antimicrobial compounds, 494 such as acetyl Sumiki's acid (Gesner et al., 2005), pyrone derivatives and macrocyclic lactones 495 (Jadulco et al., 2002). The marine-derived Cladosporium sp. F14 has also been found to produce 496 compounds, which inhibited larval settlement of the bryozoan Bugular neritina and the barnacle 497 Balanus amphitrite (Qi et al., 2009). Fusarium spp. isolated from sponge Tethya aurantium was 498 found to produce antibacterial and insecticidal compounds, such as equistins and enniatine 499 (Wiese et al., 2011). Cladosporium sp. and Fusarium sp. may similarly produce secondary 500 metabolites in the sponges investigated here, which may potentially contribute to sponge host 501 defence.

502

OTU_5 (Aureobasidium sp., order Dothideales), OTU_7 (Curvularia sp., order Pleosporales) 504 and OTU_13 (Beauveria sp., order Hypocreales) had closest sequence similarity to common terrestrial species (Table S5), which can be facultative pathogens of plants, humans and insects 506 (Zalar et al., 2008, Rinaldi et al., 1987, Liu et al., 2009, Rehner et al., 2011). All three genera 507 have been previously isolated from various sponges around the globe (Li and Wang, 2009, Wang 508 et al., 2008, Gao et al., 2008, Passarini et al., 2015, Henríquez et al., 2014, Holler et al., 2000,

509 Wiese et al., 2011). Sponges have been reported to harbour various other fungal species related 510 to terrestrial plant, human and animal pathogens, such as Aspergillus terreus and Cladosporium 511 tenuissimum (Zhou et al., 2011, Liu et al., 2010). Additionally, the sponge species Spongia 512 obsucra and Ircina strobilina have been reported to host the fungus Aspergillus sydowii, which is 513 a causative agent of a disease in the Caribbean sea fan corals (Gorgonia spp.) but had no notable 514 affect to the sponge health (Ein-Gil et al., 2009). This suggests that sponges could be reservoirs 515 of potential marine and terrestrial pathogens and may provide an environment for fungal 516 propagule survival and dispersal.

\section{Conclusion}


519 Our study shows that the sponge samples analysed here contain phylogenetically diverse fungi 520 (eight fungal classes were observed) that have low host-specificity and broadly reflected 521 communities within the seawater. The same or highly similar fungal species have been detected 522 in sponges around the world, which suggests a prevalence of horizontal transmission where 523 selectivity and enrichment of some fungi occur for those that can survive and/or exploit the 524 sponge environment. Our current (sparse) knowledge about sponge-associated fungi indicates 525 that fungal communities may perhaps not play as an important ecological role (beside the 526 exceptional case reported of vertically transmitted endosymbiotic yeast ; Maldonado et al., 2005) 527 in the sponge holobiont compared to bacteria or archaea. However, the interaction between 528 sponges and fungi provides another layer to the already complex sponge environment, which 529 may drive the evolution of not only bacteria and archaea (Thomas et al., 2016, Hentschel et al., 530 2002, Fan et al., 2012, Thomas et al., 2010), but possibly also fungi. The ecology and function of 531 sponge-associated fungi represents a frontier of microbial diversity research awaiting further 532 studies.

533

534 ACKNOWLEDGEMENT

535 The authors would like to thank Dr. Shaun Nielsen and Dr. Cristina Diez-Vives for help with 536 sponge sampling.

537

538

539

540

541

542

543

544 


\section{REFERENCE}

ABARENKOV, K., HENRIK NILSSON, R., LARSSON, K. H., ALEXANDER, I. J., EBERHARDT, U., ERLAND, S., HØILAND, K., KJØLLER, R., LARSSON, E. \& PENNANEN, T. 2010. The UNITE database for molecular identification of fungi-recent updates and future perspectives. New Phytologist, 186, 281-285.

AMEND, A. S., BARSHIS, D. J. \& OLIVER, T. A. 2012. Coral-associated marine fungi form novel lineages and heterogeneous assemblages. The ISME journal, 6, 1291-1301.

ANDERSON, I. C., CAMPBELL, C. D. \& PROSSER, J. I. 2003. Potential bias of fungal 18S rDNA and internal transcribed spacer polymerase chain reaction primers for estimating fungal biodiversity in soil. Environmental Microbiology, 5, 36-47.

ANDERSON, M. J. 2001. A new method for non-parametric multivariate analysis of variance. Austral Ecology, 26, 32-46.

ANDERSON, M. J. 2006. Distance-based tests for homogeneity of multivariate dispersions. Biometrics, 62, 245-253.

ANDERSON, M. J., ELLINGSEN, K. E. \& MCARDLE, B. H. 2006. Multivariate dispersion as a measure of beta diversity. Ecology letters, 9, 683-693.

BAKER, P. W., KENNEDY, J., DOBSON, A. D. \& MARCHESI, J. R. 2009. Phylogenetic diversity and antimicrobial activities of fungi associated with Haliclona simulans isolated from Irish coastal waters. Marine biotechnology, 11, 540-547.

BELL, J. J. 2008. The functional roles of marine sponges. Estuarine, Coastal and Shelf Science, 79, 341-353.

BORNEMAN, J. \& HARTIN, R. J. 2000. PCR primers that amplify fungal rRNA genes from environmental samples. Applied and environmental microbiology, 66, 4356-4360.

BURGAUD, G., LE CALVEZ, T., ARZUR, D., VANDENKOORNHUYSE, P. \& BARBIER, G. 2009. Diversity of culturable marine filamentous fungi from deep-sea hydrothermal vents. Environmental Microbiology, 11, 1588-1600.

COLE, J. R., WANG, Q., FISH, J. A., CHAI, B., MCGARRELL, D. M., SUN, Y., BROWN, C. T., PORRAS-ALFARO, A., KUSKE, C. R. \& TIEDJE, J. M. 2013. Ribosomal Database Project: data and tools for high throughput rRNA analysis. Nucleic acids research, gkt1244.

CROUS, P. W., GAMS, W., WINGFIELD, M. J. \& VAN WYK, P. 1996. Phaeoacremonium gen. nov. associated with wilt and decline diseases of woody hosts and human infections. Mycologia, 786-796.

DAS, M., ROYER, T. V. \& LEFF, L. G. 2008. Fungal communities on decaying leaves in streams: a comparison of two leaf species. Mycological progress, 7, 267-275.

DE BEECK, M. O., LIEVENS, B., BUSSCHAERT, P., DECLERCK, S., VANGRONSVELD, J. \& COLPAERT, J. V. 2014. Comparison and validation of some ITS primer pairs useful for fungal metabarcoding studies. PLoS One, 9, e97629. 
583

584

585

586

587

588

589

590

591

592

593

594

595

596

597

598

599

600

601

602

603

604

605

606

607

608

609

610

611

612

613

614

615

616

617

618

619

620

621

DING, B., YIN, Y., ZHANG, F. \& LI, Z. 2011. Recovery and phylogenetic diversity of culturable fungi associated with marine sponges Clathrina luteoculcitella and Holoxea sp. in the South China Sea. Marine Biotechnology, 13, 713-721.

DÖRING, H., CLERC, P., GRUBE, M. \& WEDIN, M. 2000. Mycobiont-Specific PCR Primers for the Amplification of Nuclear its and LSU rDNA from Lichenized Ascomycetes. The Lichenologist, 32, 200-204.

EDGAR, R. C. 2013. UPARSE: highly accurate OTU sequences from microbial amplicon reads. Nature methods, 10, 996-998.

EDGAR, R. C., HAAS, B. J., CLEMENTE, J. C., QUINCE, C. \& KNIGHT, R. 2011. UCHIME improves sensitivity and speed of chimera detection. Bioinformatics, 27, 2194-2200.

EIN-GIL, N., ILAN, M., CARMELI, S., SMITH, G. W., PAWLIK, J. R. \& YARDEN, O. 2009. Presence of Aspergillus sydowii, a pathogen of gorgonian sea fans in the marine sponge Spongia obscura. The ISME journal, 3, 752.

ELLESTAD, G. A., EVANS JR, R. H. \& KUNSTMANN, M. P. 1969. Structure of a C17 antifungal terpenoid from an unidentified Acrostalagmus species. Journal of the American Chemical Society, 91, 2134-2136.

ESTEVES, A. I. S., AMER, N., NGUYEN, M. \& THOMAS, T. 2016. Sample processing impacts the viability and cultivability of the sponge microbiome. Frontiers in Microbiology, 7.

FAN, L., REYNOLDS, D., LIU, M., STARK, M., KJELlEBERG, S., WEBSTER, N. S. \& THOMAS, T. 2012. Functional equivalence and evolutionary convergence in complex communities of microbial sponge symbionts. Proc Natl Acad Sci U S A, 109, E1878-87.

GAO, Z., LI, B., ZHENG, C. \& WANG, G. 2008. Molecular detection of fungal communities in the Hawaiian marine sponges Suberites zeteki and Mycale armata. Applied and Environmental Microbiology, 74, 6091-6101.

GARDES, M. \& BRUNS, T. D. 1993. ITS primers with enhanced specificity for basidiomycetes-application to the identification of mycorrhizae and rusts. Molecular ecology, 2, 113-118.

GESNER, S., COHEN, N., ILAN, M., YARDEN, O. \& CARMELI, S. 2005. Pandangolide 1a, a metabolite of the sponge-associated fungus Cladosporium sp., and the absolute stereochemistry of pandangolide 1 and iso-cladospolide B. Journal of natural products, 68, 1350-1353.

HAWKSWORTH, D. L. 1991. The fungal dimension of biodiversity: magnitude, significance, and conservation. Mycological research, 95, 641-655.

HAWKSWORTH, D. L. 2001. The magnitude of fungal diversity: the 1.5 million species estimate revisited** Paper presented at the Asian Mycological Congress 2000 (AMC 2000), incorporating the 2nd Asia-Pacific Mycological Congress on Biodiversity and Biotechnology, and held at the University of Hong Kong on 9-13 July 2000. Mycological research, 105, 1422-1432. 
622

623

624

625

626

627

628

629

630

631

632

633

634

635

636

637

638

639

640

641

642

643

644

645

646

647

648

649

650

651

652

653

654

655

656

657

658

659

660
HE, L., LIU, F., KARUPPIAH, V., REN, Y. \& LI, Z. 2014. Comparisons of the Fungal and Protistan Communities among Different Marine Sponge Holobionts by Pyrosequencing. Microbial Ecology, 67, 951-961.

HENRÍQUEZ, M., VERGARA, K., NORAMBUENA, J., BEIZA, A., MAZA, F., UBILLA, P., ARAYA, I., CHÁVEZ, R., SAN-MARTÍN, A. \& DARIAS, J. 2014. Diversity of cultivable fungi associated with Antarctic marine sponges and screening for their antimicrobial, antitumoral and antioxidant potential. World Journal of Microbiology and Biotechnology, 30, 65-76.

HENTSCHEL, U., FIESELER, L., WEHRL, M., GERNERT, C., STEINERT, M., HACKER, J. $\&$ HORN, M. 2003. Microbial diversity of marine sponges. Sponges (Porifera). Springer.

HENTSCHEL, U., HOPKE, J., HORN, M., FRIEDRICH, A. B., WAGNER, M., HACKER, J. \& MOORE, B. S. 2002. Molecular evidence for a uniform microbial community in sponges from different oceans. Applied and Environmental Microbiology, 68, 4431-4440.

HENTSCHEL, U., SCHMID, M., WAGNER, M., FIESELER, L., GERNERT, C. \& HACKER, J. 2001. Isolation and phylogenetic analysis of bacteria with antimicrobial activities from the Mediterranean sponges Aplysina aerophoba and Aplysina cavernicola. FEMS Microbiology Ecology, 35, 305-312.

HENTSCHEL, U., USHER, K. M. \& TAYLOR, M. W. 2006. Marine sponges as microbial fermenters. FEMS microbiology ecology, 55, 167-177.

HIBBETT, D., BAUER, R., BINDER, M., GIACHINI, A., HOSAKA, K., JUSTO, A., LARSSON, E., LARSSON, K.-H., LAWREY, J. D. \& MIETTINEN, O. 2014. 14 Agaricomycetes. Systematics and evolution. Springer.

HOLLER, U., WRIGHT, A. D., MATTHEE, G. F., KONIG, G. M., DRAEGER, S., AUST, H.J. \& SCHULZ, B. 2000. Fungi from marine sponges: diversity, biological activity and secondary metabolites. Mycological Research, 104, 1354-1365.

HOSOYA, T. \& TANAKA, K. 2007. Survey of freshwater hyphomycetes in Yakushima Island, southern Japan. Bulletin of the National Museum of Nature and Science, Series B (Botany), 33, 127-132.

HYDE, K. D., JONES, E. G., LEAÑO, E., POINTING, S. B., POONYTH, A. D. \& VRIJMOED, L. L. 1998. Role of fungi in marine ecosystems. Biodiversity and Conservation, 7, 1147-1161.

HYDE, K. D., JONES, E. G., LIU, J.-K., ARIYAWANSA, H., BOEHM, E., BOONMEE, S., BRAUN, U., CHOMNUNTI, P., CROUS, P. W. \& DAI, D.-Q. 2013. Families of dothideomycetes. Fungal Diversity, 63, 1-313.

IMHOFF, J. F. 2016. Natural products from marine fungi-Still an underrepresented resource. Marine drugs, 14, 19.

JADULCO, R., BRAUERS, G., EDRADA, R. A., EBEL, R., WRAY, V., SUDARSONO, A. \& PROKSCH, P. 2002. New Metabolites from Sponge-Derived Fungi Curvularia 1 unata and Cladosporium h erbarum. Journal of natural products, 65, 730-733. 
661

662

663

664

665

666

667

668

669

670

671

672

673

674

675

676

677

678

679

680

681

682

683

684

685

686

687

688

689

690

691

692

693

694

695

696

697

698

699

JEBARAJ, C. S., RAGHUKUMAR, C., BEHNKE, A. \& STOECK, T. 2010. Fungal diversity in oxygen-depleted regions of the Arabian Sea revealed by targeted environmental sequencing combined with cultivation. FEMS Microbiology Ecology, 71, 399-412.

JEEWON, R. \& HYDE, K. 2007. Detection and diversity of fungi from environmental samples: traditional versus molecular approaches. Advanced Techniques in Soil Microbiology. Springer.

KIS-PAPO, T. 2005. Marine fungal communities. Mycology Series, 23, 61.

KOHLMEYER, J. \& VOLKMANN-KOHLMEYER, B. 1990. New species of Koralionastes (Ascomycotina) from the Caribbean and Australia. Canadian Journal of Botany, 68, 1554-1559.

KOHLMEYER, J. \& VOLKMANN-KOHLMEYER, B. 1992. Two Ascomycotina from coral reefs in the Caribbean and Australia. Cryptogamic Botany, 2, 367-374.

KUBICEK, C. P., KOMON-ZELAZOWSKA, M. \& DRUZHININA, I. S. 2008. Fungal genus Hypocrea/Trichoderma: from barcodes to biodiversity. Journal of Zhejiang University Science B, 9, 753.

KULIKOVA, N., SAIBATALOVA, E., BOIKO, S., SEMITURKINA, N., BELOZEROVA, O. Y., MEKHONOSHIN, A., TIMOSHKIN, O. \& SUTURIN, A. 2013. Biogeochemistry of encrusting sponges of the family Lubomirskiidae in Southern Lake Baikal. Geochemistry International, 51, 326-337.

LEE, O. O., WANG, Y., YANG, J., LAFI, F. F., AL-SUWAILEM, A. \& QIAN, P.-Y. 2011. Pyrosequencing reveals highly diverse and species-specific microbial communities in sponges from the Red Sea. The ISME journal, 5, 650-664.

LEE, S. 1988. A rapid high yield mini-prep method for isolation of total genomic DNA from fungi. Fungal Genet. Newsl., 35, 23-24.

LI, Q. \& WANG, G. 2009. Diversity of fungal isolates from three Hawaiian marine sponges. Microbiological research, 164, 233-241.

LI, Z., HE, L. \& MIAO, X. 2007. Cultivable bacterial community from South China Sea sponge as revealed by DGGE fingerprinting and $16 \mathrm{~S}$ rDNA phylogenetic analysis. Current microbiology, 55, 465-472.

LIU, T., LIU, L., JIANG, X., HUANG, X. \& CHEN, J. 2009. A new furanoid toxin produced by Curvularia lunata, the causal agent of maize Curvularia leaf spot. Canadian Journal of Plant Pathology, 31, 22-27.

LIU, W., LI, C., ZHU, P., YANG, J. \& CHENG, K. 2010. Phylogenetic diversity of culturable fungi associated with two marine sponges: Haliclona simulans and Gelliodes carnosa, collected from the Hainan Island coastal waters of the South China Sea. Fungal Diversity, 42, 1-15.

MALDONADO, M., CORTADELlAS, N., TRILlAS, M. I. \& RÜTZLER, K. 2005. Endosymbiotic yeast maternally transmitted in a marine sponge. The Biological Bulletin, 209, 94-106. 
700

MENEZES, C. B., BONUGLI-SANTOS, R. C., MIQUELETTO, P. B., PASSARINI, M. R., SILVA, C. H., JUSTO, M. R., LEAL, R. R., FANTINATTI-GARBOGGINI, F., OLIVEIRA, V. M. \& BERLINCK, R. G. 2010. Microbial diversity associated with algae, ascidians and sponges from the north coast of São Paulo state, Brazil. Microbiological research, 165, 466-482.

MIADLIKOWSKA, J., KAUFF, F., HOFSTETTER, V., FRAKER, E., GRUBE, M., HAFELLNER, J., REEB, V., HODKINSON, B. P., KUKWA, M. \& LÜCKING, R. 2006. New insights into classification and evolution of the Lecanoromycetes (Pezizomycotina, Ascomycota) from phylogenetic analyses of three ribosomal RNA-and two protein-coding genes. Mycologia, 98, 1088-1103.

MORRISON-GARDINER, S. 2002. Dominant fungi from Australian coral reefs. Fungal Divers, 9, 105-121.

MUSCHOLL-SILBERHORN, A., THIEL, V. \& IMHOFF, J. F. 2008. Abundance and bioactivity of cultured sponge-associated bacteria from the Mediterranean Sea. Microbial Ecology, 55, 94-106.

NAIM, M. A., SMIDT, H. \& SIPKEMA, D. 2017. Fungi found in Mediterranean and North Sea sponges: how specific are they? PeerJ, 5, e3722.

NIKOLCHEVA, L. G., COCKSHUTT, A. M. \& BÄRLOCHER, F. 2003. Determining diversity of freshwater fungi on decaying leaves: comparison of traditional and molecular approaches. Applied and environmental microbiology, 69, 2548-2554.

OKSANEN, J., BLANCHET, F. G., KINDT, R., LEGENDRE, P., MINCHIN, P. R., O’HARA, R., SIMPSON, G. L., SOLYMOS, P., STEVENS, M. H. H. \& WAGNER, H. 2013. Package 'vegan'. Community ecology package, version, 2.

PANG, K.-L. \& MITCHELL, J. I. 2005. Molecular approaches for assessing fungal diversity in marine substrata. Botanica Marina, 48, 332-347.

PASSARINI, M. R., MIQUELETTO, P. B., DE OLIVEIRA, V. M. \& SETTE, L. D. 2015. Molecular diversity of fungal and bacterial communities in the marine sponge Dragmacidon reticulatum. Journal of basic microbiology, 55, 207-220.

PASSARINI, M. R., SANTOS, C., LIMA, N., BERLINCK, R. G. \& SETTE, L. D. 2013. Filamentous fungi from the Atlantic marine sponge Dragmacidon reticulatum. Archives of microbiology, 195, 99-111.

PAZ, Z., KOMON-ZELAZOWSKA, M., DRUZHININA, I., AVESKAMP, M., SHNAIDERMAN, A., ALUMA, Y., CARMELI, S., ILAN, M. \& YARDEN, O. 2010. Diversity and potential antifungal properties of fungi associated with a Mediterranean sponge. Fungal Diversity, 42, 17-26.

PIVKIN, M., ALESHKO, S., KRASOKHIN, V. \& KHUDYAKOVA, Y. V. 2006. Fungal assemblages associated with sponges of the southern coast of Sakhalin Island. Russian Journal of Marine Biology, 32, 207-213.

PROKSCH, P., EBEL, R., EDRADA, R., RIEBE, F., LIU, H., DIESEL, A., BAYER, M., LI, X., HAN LIN, W. \& GREBENYUK, V. 2008. Sponge-associated fungi and their bioactive compounds: the Suberites case. Botanica Marina, 51, 209-218. 
741

742

743

744

745

746

747

748

749

750

751

752

753

754

755

756

757

758

759

760

761

762

763

764

765

766

767

768

769

770

771

772

773

774

775

776

777

778

779

780

PROKSCH, P., EBEL, R., EDRADA, R., SCHUPP, P., LIN, W., WRAY, V. \& STEUBE, K. 2003. Detection of pharmacologically active natural products using ecology. Selected examples from Indopacific marine invertebrates and sponge-derived fungi. Pure and applied chemistry, 75, 343-352.

QI, S.-H., XU, Y., XIONG, H.-R., QIAN, P.-Y. \& ZHANG, S. 2009. Antifouling and antibacterial compounds from a marine fungus Cladosporium sp. F14. World Journal of Microbiology and Biotechnology, 25, 399.

QUAST, C., PRUESSE, E., YILMAZ, P., GERKEN, J., SCHWEER, T., YARZA, P., PEPLIES, J. \& GLÖCKNER, F. O. 2012. The SILVA ribosomal RNA gene database project: improved data processing and web-based tools. Nucleic acids research, gks1219.

REHNER, S. A., MINNIS, A. M., SUNG, G.-H., LUANGSA-ARD, J. J., DEVOTTO, L. \& HUMBER, R. A. 2011. Phylogeny and systematics of the anamorphic, entomopathogenic genus Beauveria. Mycologia, 103, 1055-1073.

RICHARDS, T. A., JONES, M. D., LEONARD, G. \& BASS, D. 2012. Marine fungi: their ecology and molecular diversity. Annual review of marine science, 4, 495-522.

RINALDI, M., PHILLIPS, P., SCHWARTZ, J., WINN, R., HOLT, G., SHAGETS, F., ELROD, J., NISHIOKA, G. \& AUFDEMORTE, T. 1987. Human Curvularia infections: report of five cases and review of the literature. Diagnostic microbiology and infectious disease, 6, 27-39.

RODRÍGUEZ-MARCONI, S., DE LA IGLESIA, R., DÍEZ, B., FONSECA, C. A., HAJDU, E. \& TREFAULT, N. 2015. Characterization of bacterial, archaeal and eukaryote symbionts from Antarctic sponges reveals a high diversity at a three-domain level and a particular signature for this ecosystem. PloS one, 10, e0138837.

ROSSMAN, A. Y., FARR, D. F. \& CASTLEBURY, L. A. 2007. A review of the phylogeny and biology of the Diaporthales. Mycoscience, 48, 135-144.

ROT, C., GOLDFARB, I., ILAN, M. \& HUCHON, D. 2006. Putative cross-kingdom horizontal gene transfer in sponge (Porifera) mitochondria. BMC Evolutionary Biology, 6, 1.

SATO, M. \& KAKISAWA, H. 1976. Structures of three new C 16 terpenoids from an Acrostalagmus fungus. Journal of the Chemical Society, Perkin Transactions 1, 24072413.

SCHLOSS, P. D., WESTCOTT, S. L., RYABIN, T., HALL, J. R., HARTMANN, M., HOLLISTER, E. B., LESNIEWSKI, R. A., OAKLEY, B. B., PARKS, D. H. \& ROBINSON, C. J. 2009. Introducing mothur: open-source, platform-independent, community-supported software for describing and comparing microbial communities. Applied and environmental microbiology, 75, 7537-7541.

SINGH, P., RAGHUKUMAR, C., MEENA, R. M., VERMA, P. \& SHOUCHE, Y. 2012. Fungal diversity in deep-sea sediments revealed by culture-dependent and culture-independent approaches. Fungal Ecology, 5, 543-553.

SRIDHAR, K. \& KAVERIAPPA, K. 1989. Water-Borne Flyphomycete Flora of Two Freshwater Streams. Environment \& Ecology, 7, 771-772. 
SUTURIN, A., TIMOSHKIN, O., PARADINA, L., KRAVTSOVA, L., ROZHKOVA, N., KULIKOVA, N., SAIBATALOVA, Y. V. \& SEMITURKINA, N. 2003. Biogeochemical Processes on the Stony Littoral-Unlimited Element and Nutrient Source for Baikal Ecosystem. Berl. Palaeobiol. Abh, 129-139.

TAYLOR, M. W., RADAX, R., STEGER, D. \& WAGNER, M. 2007. Sponge-Associated Microorganisms: Evolution, Ecology, and Biotechnological Potential. Microbiology and Molecular Biology Reviews, 71, 295-347.

THIRUNAVUKKARASU, N., SURYANARAYANAN, T. S., GIRIVASAN, K. P., VENKATACHALAM, A., GEETHA, V., RAVISHANKAR, J. P. \& DOBLE, M. 2012. Fungal symbionts of marine sponges from Rameswaram, southern India: species composition and bioactive metabolites. Fungal Diversity, 55, 37-46.

THOMAS, T., MOITINHO-SILVA, L., LURGI, M., BJÖRK, J. R., EASSON, C., ASTUDILLO-GARCÍA, C., OLSON, J. B., ERWIN, P. M., LÓPEZ-LEGENTIL, S. \& LUTER, H. 2016. Diversity, structure and convergent evolution of the global sponge microbiome. Nature Communications, 7.

THOMAS, T., RUSCH, D., DEMAERE, M. Z., YUNG, P. Y., LEWIS, M., HALPERN, A., HEIDELBERG, K. B., EGAN, S., STEINBERG, P. D. \& KJELlEBERG, S. 2010. Functional genomic signatures of sponge bacteria reveal unique and shared features of symbiosis. Isme j, 4, 1557-67.

WANG, F.-Z., HUANG, Z., SHI, X.-F., CHEN, Y.-C., ZHANG, W.-M., TIAN, X.-P., LI, J. \& ZHANG, S. 2012. Cytotoxic indole diketopiperazines from the deep sea-derived fungus Acrostalagmus luteoalbus SCSIO F457. Bioorganic \& medicinal chemistry letters, 22, 7265-7267.

WANG, G., LI, Q. \& ZHU, P. 2008. Phylogenetic diversity of culturable fungi associated with the Hawaiian sponges Suberites zeteki and Gelliodes fibrosa. Antonie Van Leeuwenhoek, 93, 163-174.

WANG, Y., TIAN, R. M., GAO, Z. M., BOUGOUFFA, S. \& QIAN, P.-Y. 2014. Optimal eukaryotic $18 \mathrm{~S}$ and universal $16 \mathrm{~S} / 18 \mathrm{~S}$ ribosomal RNA primers and their application in a study of symbiosis. PloS one, 9, e90053.

WEBSTER, J. \& WEBER, R. 2007. Introduction to fungi, Cambridge University Press.

WEBSTER, N. \& HILL, R. 2001. The culturable microbial community of the Great Barrier Reef sponge Rhopaloeides odorabile is dominated by an $\alpha$-Proteobacterium. Marine Biology, $138,843-851$.

WEBSTER, N. S. \& TAYLOR, M. W. 2012. Marine sponges and their microbial symbionts: love and other relationships. Environ Microbiol, 14, 335-46.

WIESE, J., OHLENDORF, B., BLÜMEL, M., SCHMALJOHANN, R. \& IMHOFF, J. F. 2011. Phylogenetic identification of fungi isolated from the marine sponge Tethya aurantium and identification of their secondary metabolites. Marine drugs, 9, 561-585.

WHITE, T.J., BRUNS, T., LEE, S., \& Taylor, J.. 1990. Amplification and direct sequencing of fungal ribosomal RNA genes for phylogenetics. Pp. 315-322 in PCR Protocols: A Guide 
WILKINSON, C. \& FAY, P. 1979. Nitrogen fixation in coral reef sponges with symbiotic cyanobacteria.

YU, Z., ZHANG, B., SUN, W., ZHANG, F. \& LI, Z. 2013. Phylogenetically diverse endozoic fungi in the South China Sea sponges and their potential in synthesizing bioactive natural products suggested by PKS gene and cytotoxic activity analysis. Fungal Diversity, 58, $127-141$.

ZALAR, P., GOSTINČAR, C., DE HOOG, G., URŠIČ, V., SUDHADHAM, M. \& GUNDECIMERMAN, N. 2008. Redefinition of Aureobasidium pullulans and its varieties. Studies in Mycology, 61, 21-38.

ZHANG, L., KANG, M., HUANG, Y. \& YANG, L. 2016. Fungal communities from the calcareous deep-sea sediments in the Southwest India Ridge revealed by Illumina sequencing technology. World Journal of Microbiology and Biotechnology, 32, 1-11.

ZHANG, N., CASTLEBURY, L. A., MILLER, A. N., HUHNDORF, S. M., SCHOCH, C. L., SEIFERT, K. A., ROSSMAN, A. Y., ROGERS, J. D., KOHLMEYER, J. \& VOLKMANN-KOHLMEYER, B. 2006. An overview of the systematics of the Sordariomycetes based on a four-gene phylogeny. Mycologia, 98, 1076-1087.

ZHOU, K., ZHANG, X., ZHANG, F. \& LI, Z. 2011. Phylogenetically diverse cultivable fungal community and polyketide synthase (PKS), non-ribosomal peptide synthase (NRPS) genes associated with the South China Sea sponges. Microbial ecology, 62, 644-654. 


\section{Figure Legends}

844 Figure 1: Presence (black)-absence (white) map of the fungal OTUs obtained from ITS845 amplicon sequencing (brown) and cultivation (green) for samples (biological triplicates) 846 collected in 2014. Columns were clustered based on Bray-Curtis dissimilarity using hierarchical 847 clustering with the 'average' method (scale depicts the percentage of dissimilarity). Samples are 848 indicated in purple: C. concentrica, orange: Scopalina sp., blue: seawater and red: T. anhelans. 849 Numbers 1, 2 and 3 indicate sample replicates.

850

851 Figure 2: Heatmap of 'variable/core' sponge fungal communities, with OTUs only found in 852 seawater removed. Values are fourth roots of the relative abundance. Columns are clustered 853 based on Bray-Curtis dissimilarity using hierarchical clustering with the 'average' method (scale 854 depicts percentage of dissimilarities). OTUs in teal indicate sponge enriched OTUs (relative 855 abundances) compared to seawater and OTUs in maroon indicate OTUs present in sponges 856 which were absent in seawater. Samples are indicated by the colour purple: C. concentrica, 857 orange: Scopalina sp., blue: seawater and red: T. anhelans. Temporal samples are indicated by 858 the colour pink: 2014 and green: 2016. Numbers 1, 2 and 3 refer to individual replicates of each 859 sample type.

860 Figure 3: Heatmap of the bacterial community composition based on 16S rRNA gene sequences 861 for the sponge samples collected in 2014. OTUs were clustered at $97 \%$ similarity and the lowest taxonomy classification are given. Columns are clustered based on Bray-Curtis dissimilarity

863 using hierarchical clustering with the 'average' method (scale depicts percentage of 864 dissimilarities). Samples are indicated in purple: C. concentrica, orange: Scopalina sp., blue: 865 seawater and red: T. anhelans. Numbers 1, 2 and 3 indicate sample replicates. 


\section{Table $\mathbf{1}$ (on next page)}

Number of reads, observed fungal OTUs, expected fungal OTUs (Chao1),

Coverage (Good's coverage) and Shannon's index in seawater and sponge samples at a $97 \%$ sequences similarity threshold. 
1 Table 1: Number of reads, observed fungal OTUs, expected fungal OTUs (Chao1), Coverage

2 (Good's coverage) and Shannon's index in seawater and sponge samples at a 97\% sequences 3 similarity threshold.

4

\begin{tabular}{|c|c|c|c|c|c|c|c|}
\hline Sample name & $\begin{array}{l}\text { Abbreviati } \\
\text { on }\end{array}$ & $\begin{array}{l}\text { Total } \\
\text { no. of } \\
\text { quality- } \\
\text { filtered } \\
\text { reads }\end{array}$ & $\begin{array}{l}\text { No. of } \\
\text { fungal } \\
\text { reads }\end{array}$ & $\begin{array}{l}\text { Observed } \\
\text { fungal } \\
\text { OTUs }\end{array}$ & $\begin{array}{l}\text { Expected } \\
\text { OTUs } \\
\text { (Chao1) } \pm \\
\text { SE } \\
\text { (sub- } \\
\text { sampled) }\end{array}$ & $\begin{array}{l}\text { Good's } \\
\text { coverage } \\
\text { (sub- } \\
\text { sampled) }\end{array}$ & $\begin{array}{l}\text { Shannon's } \\
\text { index (sub- } \\
\text { sampled) }\end{array}$ \\
\hline C. concentrica 12014 & $\begin{array}{lll}\text { C } & 1 & 14\end{array}$ & 16199 & 14849 & 8 & $3 \pm 0$ & 1.00 & 0.09 \\
\hline C. concentrica 22014 & $\mathrm{C}^{-} 2-14$ & 3026 & 1120 & 4 & $3 \pm 0$ & 1.00 & 0.90 \\
\hline C. concentrica 32014 & C_3_14 & 6198 & 4808 & 4 & $1 \pm 0$ & 1.00 & 0.00 \\
\hline C. concentrica 12016 & $\mathrm{C}^{-} 1-16$ & 6578 & 269 & 24 & $28 \pm 18$ & 0.97 & 1.94 \\
\hline C. concentrica 22016 & $\mathrm{C}^{-} 2-16$ & 21700 & 3437 & 27 & $10 \pm 3$ & 0.99 & 0.63 \\
\hline C. concentrica 32016 & C_3 316 & 9483 & 320 & 30 & $44 \pm 35$ & 0.94 & 2.07 \\
\hline Scopalina sp. 12014 & S_1_14 & 1532 & 49 & 2 & NA & NA & NA \\
\hline Scopalina sp. 22014 & $\mathrm{~S}^{-}{ }^{-} 14$ & 7071 & 12 & 3 & NA & NA & NA \\
\hline Scopalina sp. 32014 & $\mathrm{~S}^{-} 3-14$ & 1992 & 107 & 4 & NA & NA & NA \\
\hline Scopalina sp. 12016 & S_1 16 & 4859 & 444 & 29 & $27 \pm 15$ & 0.97 & 1.33 \\
\hline Scopalina sp. 22016 & S_2_16 & 3281 & 206 & 32 & NA & NA & NA \\
\hline Scopalina sp. 32016 & $\mathrm{~S}^{-} 3-16$ & 24565 & 665 & 36 & $39 \pm 50$ & 0.96 & 1.38 \\
\hline T. anhelans 12014 & $\mathrm{~T}_{-1}^{-} 14$ & 681 & 681 & 2 & $2 \pm 1$ & 1.00 & 0.03 \\
\hline T. anhelans 22014 & T_2_14 & 6947 & 6703 & 9 & $5 \pm 4$ & 1.00 & 0.96 \\
\hline T. anhelans 32014 & $\mathrm{~T}^{-} 3 \mathrm{-} 14$ & 64 & 8 & 3 & NA & NA & NA \\
\hline T. anhelans 12016 & $\mathrm{~T}^{-} 1-16$ & 19481 & 18300 & 21 & $5 \pm 4$ & 1.00 & 1.21 \\
\hline T. anhelans 22016 & $\mathrm{~T}_{-}^{-}{ }_{-}^{-} 16$ & 16379 & 6947 & 27 & $9 \pm 17$ & 0.99 & 0.77 \\
\hline T. anhelans 32016 & $\mathrm{~T} \_3 \_16$ & 30977 & 30956 & 19 & $3 \pm 2$ & 1.00 & 0.72 \\
\hline Seawater 12014 & $\mathrm{SW}^{-}{ }^{-1} 14$ & 1066 & 2 & 2 & NA & NA & NA \\
\hline Seawater 22014 & $\mathrm{SW}^{-2} 14$ & 3379 & 3314 & 2 & $2 \pm 1$ & 1.00 & 0.03 \\
\hline Seawater 32014 & SW_3_14 & 2647 & 1588 & 3 & $1 \pm 0$ & 1.00 & 0.00 \\
\hline Seawater 12016 & SW_1_16 & 6139 & 3379 & 33 & $12 \pm 8$ & 1.00 & 2.05 \\
\hline Seawater 22016 & SW_2_16 & 12439 & 5576 & 45 & $21 \pm 9$ & 0.98 & 2.37 \\
\hline Seawater 32016 & $\mathrm{SW}^{-3} 16$ & 25069 & 19496 & 40 & $14 \pm 18$ & 0.99 & 1.24 \\
\hline
\end{tabular}




\section{Table 2 (on next page)}

Number of total, transient, resident and core OTUs observed in sponge and seawater replicates.

Numbers in brackets are the sum of the mean relative abundances of reads (percentages \pm standard deviations). 
1 Table 2: Number of total, occasional, variable and core OTUs observed in sponge and seawater

2 replicates. Numbers in brackets are the sum of the mean relative abundances of reads

3 (percentages \pm standard deviations).

\begin{tabular}{lllll}
\hline Sample type & $\begin{array}{l}\text { Total } \\
\text { OTUs }\end{array}$ & Occasional OTUs & Variable OTUs & Core OTUs \\
\hline C. concentrica & 52 & $24(11.0 \% \pm 5.2)$ & $28(88.9 \% \pm 13)$ & $0(0 \%)$ \\
Scopalina sp. & 56 & $27(35.7 \% \pm 9.3)$ & $29(64.2 \% \pm 10.7)$ & $0(0 \%)$ \\
$\boldsymbol{T}$. anhelans & 49 & $32(11.9 \% \pm 5.4)$ & $16(73.2 \% \pm 10.2)$ & $1(19.5 \% \pm 35)$ \\
Seawater & 76 & $44(5 \% \pm 3.7)$ & $32(94 \% \pm 13.7)$ & 0 \\
\hline
\end{tabular}

4

5 


\section{Table 3(on next page)}

Alpha diversity of 'resident/core' fungal community as measured by the mean Shannon's index \pm standard deviation (SD).

Comparison of diversity between samples were calculated with ANOVA and multiple comparison with Tukey's test of subsampled resident/core fungal communities at an OTUlevel clustered at $97 \%$. P-values smaller than 0.05 are shown in bold. 
1 Table 3: Alpha diversity of 'variable/core' fungal community as measured by the mean 2 Shannon's index \pm standard deviation (SD). Comparison of diversity between samples were 3 calculated with ANOVA and multiple comparison with Tukey's test of subsampled resident/core 4 fungal communities at an OTU-level clustered at 97\%. P-values smaller than 0.05 are shown in 5 bold.

\begin{tabular}{|c|c|}
\hline Temporal samples & Shannon's Index (P-values) \\
\hline 2014 vs. 2016 & $0.011 \pm 0.014$ vs. $1.35 \pm 0.66$ (6.96e-05) \\
\hline C. concentrica 2014 vs. 2016 & $0.008 \pm 0.015$ vs. $1.41 \pm 0.9(\mathbf{0 . 0 4})$ \\
\hline Scopalina sp. 2014 vs. 2016 & NA vs. $1.38 \pm 0.0001(\mathrm{NA})$ \\
\hline T. anhelans 2014 vs. 2016 & $0.013 \pm 0.018$ vs. $0.75 \pm 0.45(0.62)$ \\
\hline Seawater 2014 vs. 2016 & $0.013 \pm 0.018$ vs. $1.89 \pm 0.39(\mathbf{0 . 0 1})$ \\
\hline \multicolumn{2}{|l|}{ Sample type } \\
\hline Seawater vs. Scopalina sp. & $0.45 \pm 0.52$ vs. $1.38 \pm 0.0001(0.98)$ \\
\hline T. anhelans vs. Scopalina sp. & $1.14 \pm 1.06$ vs. $1.38 \pm 0.0001(0.58)$ \\
\hline T. anhelans vs. Seawater & $1.14 \pm 1.06$ vs. $0.45 \pm 0.52(0.59)$ \\
\hline Scopalina sp. vs. C. concentrica & $1.38 \pm 0.0001$ vs. $0.71 \pm 0.96(0.77)$ \\
\hline Seawater vs. $C$. concentrica & $0.45 \pm 0.52$ vs. $0.71 \pm 0.96(0.84)$ \\
\hline T. anhelans vs. $C$. concentrica & $1.14 \pm 1.06$ vs. $0.71 \pm 0.96(0.96)$ \\
\hline
\end{tabular}

6 


\section{Table 4 (on next page)}

PERMANOVA analysis (based on relative abundance and presence-absence values) of 'resident/core' fungal communities (normalized) at an OTU-level cluster at $97 \%$ similarity of sponges and seawater samples.

P-values smaller than 0.05 are shown in bold. 
1 Table 4: PERMANOVA analysis (based on relative abundance and presence-absence values) of 2 'variable/core' fungal communities (normalized) at an OTU-level cluster at $97 \%$ similarity of 3 sponges and seawater samples. P-values smaller than 0.05 are shown in bold.

\begin{tabular}{|c|c|c|}
\hline Temporal samples & $\begin{array}{l}\text { P-value base on } \\
\text { relative abundance }\end{array}$ & $\begin{array}{l}\text { P-value based on } \\
\text { presence-absence }\end{array}$ \\
\hline 2014 vs. 2016 & 0.023 & 0.001 \\
\hline C. concentrica 2014 vs. 2016 & 0.1 & 0.001 \\
\hline Scopalina sp. 2014 vs. 2016 & NA & NA \\
\hline T. anhelans 2014 vs. 2016 & 0.40 & 0.40 \\
\hline Seawater 2014 vs. 2016 & 0.1 & 0.008 \\
\hline \multicolumn{3}{|l|}{ Sample type } \\
\hline C. concentrica vs. Scopalina sp. & 0.4 & 0.386 \\
\hline C. concentrica vs. $T$. anhelans & 0.24 & 0.154 \\
\hline C. concentrica vs. seawater & 0.54 & 0.632 \\
\hline Scopalina sp. vs. T. anhelans & 0.048 & 0.048 \\
\hline Scopalina sp. vs. seawater & 0.5 & 0.338 \\
\hline T. anhelans vs. seawater & 0.143 & 0.139 \\
\hline
\end{tabular}

4 


\section{Figure 1}

Presence (black)-absence (white) map of the fungal OTUs obtained from ITS-amplicon sequencing (brown) and cultivation (green) for samples (biological triplicates) collected in 2014.

Columns were clustered based on Bray-Curtis dissimilarity using hierarchical clustering with the 'average' method (scale depicts the percentage of dissimilarity). Samples are indicated in purple: C. concentrica, orange: Scopalina sp., blue: seawater and red: T. anhelans. Numbers 1, 2 and 3 indicate sample replicates.

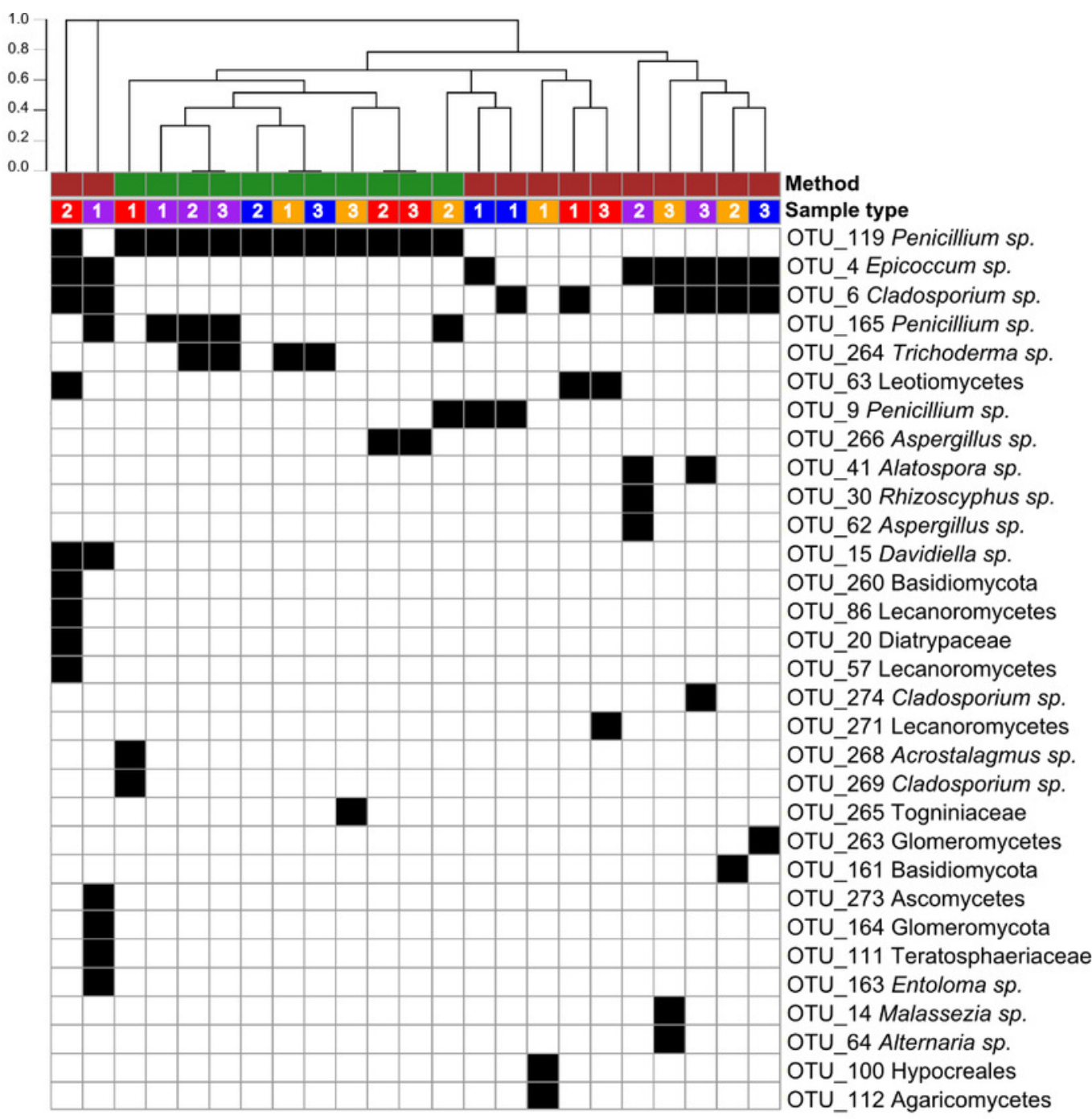

\section{Method}

ITS amplicon sequencing

Cultivation

\section{Sample type}

C. concentrica

Scopalina sp.

T. ahelans

Seawater 


\section{Figure 2}

Heatmap of 'resident/core' sponge fungal communities, with OTUs only found in seawater removed.

Values are fourth roots of the relative abundance. Columns are clustered based on BrayCurtis dissimilarity using hierarchical clustering with the 'average' method (scale depicts percentage of dissimilarities). OTUs in teal indicate sponge enriched OTUs (relative abundances) compared to seawater and OTUs in maroon indicate OTUs present in sponges which were absent in seawater. Samples are indicated by the colour purple: $C$. concentrica, orange: Scopalina sp., blue: seawater and red: T. anhelans. Temporal samples are indicated by the colour pink: 2014 and green: 2016. Numbers 1, 2 and 3 refer to individual replicates of each sample type.

OTU ID Division; Lowest taxon classification

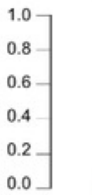

6 Ascomycota;Cladosporium sp.

3 Basidiomycota; Sporidiobolus sp.

5 Ascomycota; Aureobasidium sp.

10 Ascomycota; Pleosporales

4 Ascomycota; Epicoccum sp.

63 Ascomycota; Leotiomycetes

23 Ascomycota; Metarhizium sp.

50 Ascomycota; Lecanoromycetes

45 Ascomycota; Lecanoromycetes

87 Ascomycota; Lecanoromycetes

142 Basidiomycota; Agaricomycetes

51 Ascomycota

59 Basidiomycetes; Malassezia sp.

19 Unclassified fungi

37 Ascomycota; Lecanoromycetes

60 Unclassified fungi

14 Basidiomycota; Agaricomycetes

21 Zygomycota; Mortierella sp.

38 Basidiomycota; Coriolopsis sp.

40 Ascomycota; Lecanoromycetes

24 Unclassified fungi

28 Basidiomycota; Cryptococcus sp.

27 Basidiomycota; Cryptococcus sp.

12 Basidiomycota; Agaricales

7 Ascomycota; Curvularia sp.

18 Ascomycota; Mycosphaerella sp.

16 Ascomycota; Aspergillus sp.

11 Unclassified fungi

8 Ascomycota; Fusarium sp.

13 Ascomycota; Beauveria sp.

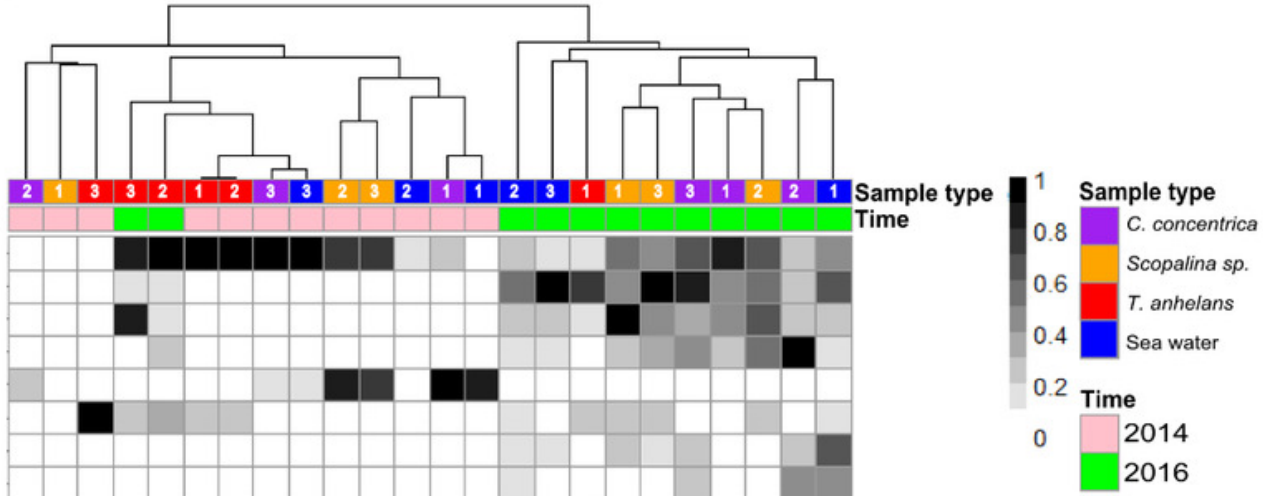




\section{Figure 3}

Heatmap of the bacterial community composition based on 16S rRNA gene sequences for the sponge samples collected in 2014.

OTUs were clustered at $97 \%$ similarity and the lowest taxonomy classification are given. Columns are clustered based on Bray-Curtis dissimilarity using hierarchical clustering with the 'average' method (scale depicts percentage of dissimilarities). Samples are indicated in purple: $C$. concentrica, orange: Scopalina sp., blue: seawater and red: T. anhelans. Numbers 1, 2 and 3 indicate sample replicates. 
OTU ID Lowest taxon OTU 01 Betaproteobacteria OTU 03 Bacteria unclassified OTU 06 Betaproteobacteria OTU 12 Bacteria unclassified OTU 17 Betaproteobacteria OTU 14 Thiohalorhabdales OTU 10 HTCC sp.

OTU 11 Proteobacteri OTU 29 Coraliomargarita sp. OTU 87 Hellea baineolensis OTU 25 Nitrosopumilus $s p$. OTU 84 Bdellovibrio sp. OTU 43 Sphingomonadales OTU 49 Opitutus sp.

OTU 56 Gammaproteobacteria OTU 59 Hyphomonadaceae OTU 50 Gammaproteobacteria OTU 78 HTCC sp.

OTU 20 Gammaproteobacteria OTU 35 Rhizobiales OTU 09 Rhodobacteraceae OTU 05 Pelagibacteraceae OTU 07 Endozoicomonas sp. OTU 04 Thiohalorhabdales OTU 13 Betaproteobacteria OTU 46 Pelagibacter sp. OTU 60 Rhodobacteraceae OTU 79 Spongiibacter $s p$. OTU 27 Flavobacteriaceae OTU 15 Flavobacteriaceae OTU 19 Candidatus Portiera sp. OTU 63 Spongiibacter tropicus OTU 85 Methylotenera sp. OTU 80 Methylophilaceae OTU 86 ZD0117sp.

OTU 83 Flavobacteriaceae OTU 62 Methylotenera sp. OTU 36 ZA3312c sp. OTU 37 Oleibacter $s p$. OTU 53 Alphaproteobacteria OTU 41 Flavobacteriaceae OTU 69 Flavobacteriaceae OTU 68 Flavobacteriaceae OTU 52 Flavobacteriaceae OTU 31 Formosa sp.

OTU 91 OM60 sp.

OTU 54 Rhodobacteraceae OTU 21 Thiohalorhabdales OTU 33 Bacteria unclassified OTU 48 Hellea baineolensis

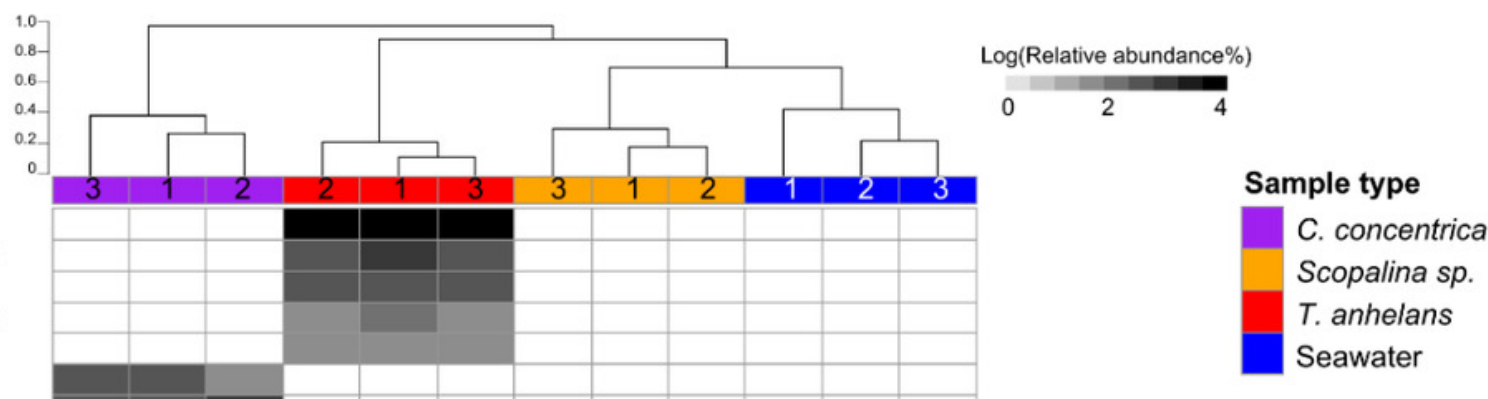

